\title{
Retraining of the 1232 Main Dipole Magnets in the LHC
}

\author{
A. Verweij, B. Auchmann, M. Bednarek, L. Bottura, Z. Charifoulline, S. Feher, P. Hagen, M. Modena, S. Le Naour, \\ I. Romera, A. Siemko, J. Steckert, J.Ph. Tock, E. Todesco, G. Willering, and D. Wollmann
}

\begin{abstract}
The Large Hadron Collider (LHC) contains eight main dipole circuits, each of them with 154 dipole magnets powered in series. These 15-m-long magnets are wound from NbTi superconducting Rutherford cables, and have active quench detection triggering heaters to quickly force the transition of the coil to the normal conducting state in case of a quench, and hence reduce the hot spot temperature. During the reception tests in 2002-2007 all these magnets have been trained up to at least $12 \mathrm{kA}$, corresponding to a beam energy of 7.1 TeV. After installation in the accelerator, the circuits have been operated at reduced currents of up to $6.8 \mathrm{kA}$ from $2010-2013$, corresponding to a beam energy of $4 \mathrm{TeV}$. After the first Long Shutdown of 2013-2014, the LHC runs at $6.5 \mathrm{TeV}$, requiring a dipole magnet current of $11.0 \mathrm{kA}$. A significant number of training quenches was needed to bring the $\mathbf{1 2 3 2}$ magnets up to this current. In this paper, the circuit behavior in case of a quench is presented, as well as the quench training as compared to the initial training during the reception tests of the individual magnets.
\end{abstract}

Index Terms-accelerator magnet, quench protection, superconducting coil

\section{INTRODUCTION}

$\mathrm{T}$ HE Large Hadron Collider (LHC) accommodates 1232 main superconducting twin-aperture dipole magnets, which are powered in eight independent circuits, each stretching over one sector of $3 \mathrm{~km}$ length [1]. The 154 dipole magnets in each sector are housed in 27 cryogenic cells, and operate in a static bath of pressurized helium II, cooled by heat exchange with flowing saturated helium II. The cold part of each circuit contains as well four $13 \mathrm{kA}$ gas cooled current leads incorporating stacks of Bi-2223 tape [2], and a large number of busbar cables, linking the dipoles together. Each circuit (see Fig. 1) is powered by a $13 \mathrm{kA}$ power converter.

The coils of these magnets consist of an inner and outer layer, wound from two types of $\mathrm{Nb}-\mathrm{Ti}$ superconducting keystoned Rutherford cable; see Table I. The inner and outer cables have been produced by different firms [3], according to the same functional specification. The 1232 magnets (plus spares) have been assembled by three different manufacturers [4], in the following denoted as Firm-1, Firm-2 and Firm-3, with only a few minor differences in tooling and procedures.

Manuscript received Oct 18, 2015

A. Verweij, B. Auchmann, M. Bednarek, L. Bottura, Z. Charifoulline, P. Hagen, M. Modena， S. Le Naour， I. Romera， A. Siemko, J. Steckert, J.Ph. Tock, E. Todesco, G. Willering, and D. Wollmann are with CERN, Switzerland. S. Feher with FNAL, US

(e-mail: Arjan.Verweij@cern.ch; phone: 0041-22-7679423)
The magnets have a nominal central field of $8.33 \mathrm{~T}$ at a current of $11.85 \mathrm{kA}$, corresponding to a beam energy of $7 \mathrm{TeV}$; see Table II. The inductance of a single circuit is $15.4 \mathrm{H}$ and its total stored energy equals $1.1 \mathrm{GJ}$ at nominal current. The protection of the dipoles and the circuit is ensured by individual quench detection systems [5], cold by-pass diodes, quench heaters, and two independent energy-extraction systems [6], and is described in more detail in Section II.

All dipole magnets have been individually tested at CERN in the years 2002-2007 especially regarding field uniformity and quench behavior [7]. A brief summary of the results of these reception tests is presented in Section III. Note that the data in this paper are based on the 1232 dipole magnets that are presently installed in the LHC, not taking into account the 44 spare magnets. About $10 \%$ of the magnets were re-trained after one or more thermal cycles. After the reception tests the magnets were stored up to several years before being installed in the LHC.

After installation in the LHC tunnel, all main dipole circuits were tested without beam during the so called 'hardware commissioning phase' [8],[9], in order to verify the proper functioning of all hardware and software associated with the circuits and ensure a safe and efficient machine start-up.

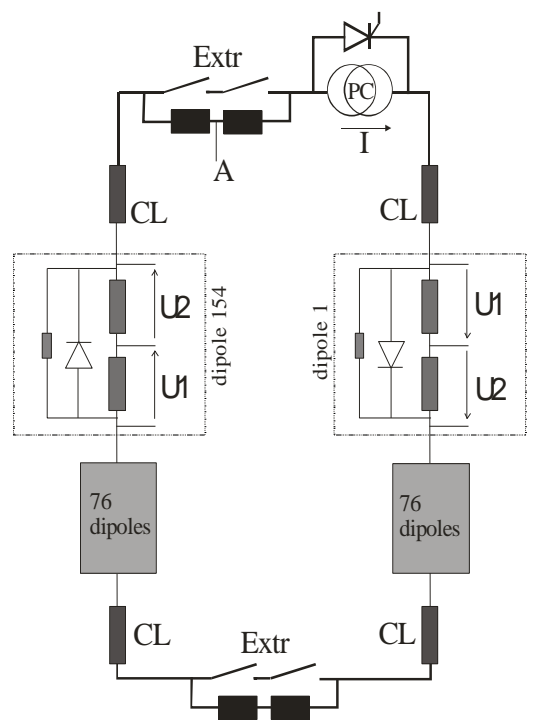

Fig. 1. Schematic view of a dipole circuit of one sector of the LHC. Note that only the first and last dipoles of the circuit are shown in more detail. The system is grounded at point A by a circuit of resistances and a fuse. Each dipole is bypassed by a cold diode and shunted by a $100 \Omega$ damping resistance. $\mathrm{PC}=$ Power Converter; $\mathrm{CL}=$ Current Lead; Extr=Energy Extraction system. 
TABLE I

Main SPECIFICATIONS OF THE CABLES USED FOR THE LHC DiPOLE MAGNETS [1]

\begin{tabular}{lll}
\hline \hline & Inner coil & Outer coil \\
\hline Cable width & $15.1 \mathrm{~mm}$ & $15.1 \mathrm{~mm}$ \\
Mid-thickness & $1.90 \mathrm{~mm}$ & $1.48 \mathrm{~mm}$ \\
Number of strands & 28 & 36 \\
Cable insulation & 2 layers of 50.8- $\mu$ m-thick polyimide with 50\% \\
& overlap, and 1 layer of 68.6- $\mu$ m-thick \\
& polyimide with 2 mm spacing \\
\hline \hline
\end{tabular}

TABLE II

Main Specifications of the LHC Dipole Magnets [1]

\begin{tabular}{ll}
\hline \hline Nominal central field & $8.33 \mathrm{~T}$ \\
Nominal current & $11850 \mathrm{~A}$ \\
Operating temperature & $1.9 \mathrm{~K}$ \\
Magnetic length & $14.312 \mathrm{~m}$ \\
Inductance at nominal field & $98.7 \mathrm{mH}$ \\
Stored energy at nominal field & $6.93 \mathrm{MJ}$ \\
Number of turns per pole, inner layer & 15 \\
Number of turns per pole, outer layer & 25 \\
Inner coil diameter & $56 \mathrm{~mm}$ \\
Distance between aperture axes & $194 \mathrm{~mm}$ \\
Bending radius & $2804 \mathrm{~m}$ \\
\hline \hline
\end{tabular}

During this first commissioning phase, only one of the eight circuits (denoted as S56) was trained up to $11.2 \mathrm{kA}$ (see Section IV), whereas the other seven circuits were only tested up to $9.3 \mathrm{kA}$. The incident in September 2008 [10] resulted in serious damage of one sector and revealed a systematic problem in the busbar connections of the main dipole and quadrupole circuits. To avoid similar problems, the magnets were operated in 2010-2012 at a reduced current of up to $6.8 \mathrm{kA}$, corresponding to a beam energy of $4 \mathrm{TeV}$. During the first Long Shutdown of 2013-2014, all busbar interconnects were consolidated and reinforced with additional copper shunts [11]. In the coming years the LHC is planned to be operated at a beam energy of $6.5 \mathrm{TeV}$, requiring a dipole magnet current of $10980 \mathrm{~A}$. In the beginning of 2015, all eight circuits have therefore been retrained to this current plus a small margin of $100 \mathrm{~A}$, i.e. $11080 \mathrm{~A}$, requiring 175 training quenches. The results of these training quenches are presented in Section V and compared to the training during the reception tests and the training in S56 in 2008.

\section{Protection In CASE OF A Quench}

The protection of the dipole magnets relies on fast and reliable detection of resistive voltages based on a floating bridge detector, which continuously compares the voltages U1 and $\mathrm{U} 2$ of the two apertures [5]. As soon as the differential voltage U1-U2 reaches the threshold voltage ( $200 \mathrm{mV}$ for the reception tests and $100 \mathrm{mV}$ in the $\mathrm{LHC}$ ), the quench detection is triggered (after a short evaluation time of about $10 \mathrm{~ms}$ ), initiating within $5 \mathrm{~ms}$ a discharge of the quench-heater power supplies of the quenching magnet. At the same time the
Powering Interlock Controller switches off the power converter, after which a bypass thyristor across the converter terminal ensures the circuit continuity. About $20-50 \mathrm{~ms}$ later the heat developed in the quench heaters causes the transition to the normal state of a large part of the coil of the quenching magnet. The resistive voltage build-up in the coils opens the bypass diodes and causes a fast decay of the current in the quenched magnet.

In the LHC the circuits are composed of 154 magnets in series, and the circuit current cannot be discharged at the same rate as the current in the quenching magnet. The circuit protection is therefore ensured by additional cold bypass diodes, and two energy extraction systems [6]; see Fig. 1. As soon as the voltage over the quenching magnet reaches the turn-on voltage of the bypass diode of about $6 \mathrm{~V}$ (at $1.9 \mathrm{~K}$ ), the diode starts to conduct, and the current in the quenching magnet commutes into the diode within a few $100 \mathrm{~ms}$. The switches of the two energy extraction systems are triggered about 350 and $600 \mathrm{~ms}$ after quench detection, respectively, and, due to the two additional dump resistances of $75 \mathrm{~m} \Omega$ each, the circuit current decays with a time constant of about $100 \mathrm{~s}$. During this decay the current bypasses the quenched magnet, warming up the cold diode, whose forward voltage quickly drops from $6 \mathrm{~V}$ to $1 \mathrm{~V}$ when heating up.

During the decay of the circuit current, heat flow from the quenching magnet usually causes secondary quenches of neighbouring magnets located in the same cryogenic cell, as soon as the temperature of a part of the coil raises above the current sharing temperature. Most adjacent quenches occur after about 40-100 s at currents of about 4-8 kA. During the quench event, the pressure rise due to the increase in helium temperature is limited to about 18 bar by means of a relief valve.

\section{TRAINING DURING RECEPTION TESTS}

When a superconducting magnet is powered for the first time it may not reach the short sample limit of the conductor, but quenches before. During successive quenches the current that is reached usually increases, a process which is called training, and generally believed to be due to the setting of the conductor or coil in a more stable position. During the reception tests in 2002-2007 all magnets were individually cooled down to $1.9 \mathrm{~K}$ and ramped up with $10 \mathrm{~A} / \mathrm{s}$ until a quench would occur, or until $12850 \mathrm{~A}$ was reached. Due to time constraints, the training of about half of the magnets was stopped between $12000 \mathrm{~A}$ and $12850 \mathrm{~A}$ [12]. In total 1115 quenches were needed to train to the nominal current of $11850 \mathrm{~A}$; see Table III. In order to compare the training during reception with the training in the LHC (see Section V), also the number of quenches needed to reach $11080 \mathrm{~A}$ was calculated, which equals 413 . Sorting all quench data of the individual magnets by increasing quench current, makes it possible to build a training curve as if the magnets of each firm were put in series. The result is shown in Fig. 2, in which the number of quenches in Firm-1, Firm-2 and Firm-3 is normalized to the number of magnets, i.e. 400,420 , and 412 respectively. The majority of the magnets required none or a single quench to reach $11080 \mathrm{~A}$, and only 1\% for Firm-1, 5\% 
for Firm-2, and $8 \%$ for Firm-3 needed 2 or 3 quenches. Similarly, on average $95 \%$ of the magnets needed 0,1 or 2 quenches to reach $11850 \mathrm{~A}$, and only $3 \%$ for Firm-1, and $6 \%$ for Firm-2 and Firm-3 needed 3 to 6 quenches. The data show a significant difference among the three firms. Firm- 1 magnets trained 2 and 1.6 times faster up to 11850 A than Firm-2 and Firm-3 respectively. Similarly, Firm-1 magnets trained 3.9 times faster up to 11080 A than the other two firms.

TABLE III

Quench BeHAVIOR OF THE 1232 Dipole MAgNets DuRING THE INDIVIDUAL RECEPTION TESTS

\begin{tabular}{lllll}
\hline \hline & Firm-1 & Firm-2 & Firm-3 & All \\
\hline Number of magnets & 400 & 420 & 412 & 1232 \\
Nr quenches to reach 11850 A & 244 & 485 & 386 & 1115 \\
Nr quenches to reach 11080 A & 47 & 183 & 183 & 413 \\
\hline \hline
\end{tabular}

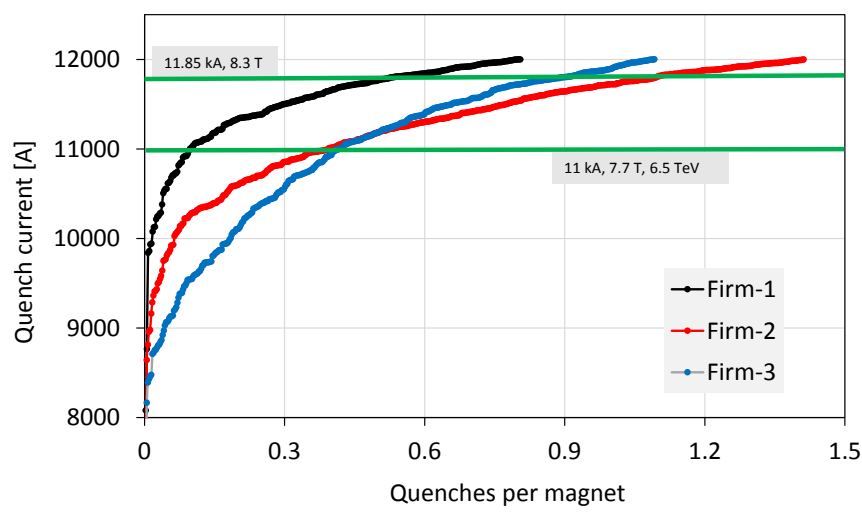

Fig. 2. Training curve to $12 \mathrm{kA}$ for the 1232 dipole magnets presently installed in the LHC.

666 out of the 1232 magnets have also been tested up to $12850 \mathrm{~A}$, see Table IV, showing that this current was reached for the three firms in about 4 quenches per magnet on average.

TABLE IV

Quench BeHAVior of THE 666 Dipole Magnets During the INDIVIDUAL RECEPTION TESTS THAT WERE TRAINED TO $12850 \mathrm{~A}$

\begin{tabular}{lllll}
\hline \hline & Firm-1 & Firm-2 & Firm-3 & All \\
\hline Number of magnets & 166 & 243 & 257 & 666 \\
Nr quenches to reach 12850 A & 591 & 1032 & 961 & 2584 \\
Nr quenches / Nr of magnets & 3.56 & 4.25 & 3.74 & 3.88 \\
\hline \hline
\end{tabular}

Almost $10 \%$ of all magnets have been re-trained after a thermal cycle, usually within a few weeks of the first cooldown, and without removing the magnets from the test station. These magnets were in most cases those that trained slower during the first cool-down (but always reached at least $12 \mathrm{kA}$ ) and are therefore not a representative subset of all the magnets. The overview in Table $\mathrm{V}$ clearly shows that the number of training quenches needed to reach $11850 \mathrm{~A}$ was about $240 / 37=6.5$ times less during the $2^{\text {nd }}$ cool-down than during the $1^{\text {st }}$ cool-down. A reduction of a factor of $68 / 8=8.5$ was observed when comparing the quenches required to reach 11080 A. The magnets therefore showed a good memory, at least over a period of several weeks, irrespective of the magnet manufacturer.

TABLE V

Quench Behavior of THE 116 Dipole Magnets that HaVe BeEN Re-TESTED AFTER A THERMAL CyCle

\begin{tabular}{|c|c|c|c|c|}
\hline & Firm-1 & Firm-2 & Firm-3 & All \\
\hline Number of magnets & 33 & 55 & 28 & 116 \\
\hline $\mathrm{Nr}$ quenches to reach $11850 \mathrm{~A}$ & & & & \\
\hline $\begin{array}{c}\text { during the } 1^{\text {st }} \text { cool-down } \\
\mathrm{Nr} \text { quenches to reach } 11850 \mathrm{~A}\end{array}$ & 54 & 119 & 67 & 240 \\
\hline during the $2^{\text {nd }}$ cool-down & 6 & 21 & 10 & 37 \\
\hline $\begin{array}{l}\mathrm{Nr} \text { quenches to reach } 11080 \mathrm{~A} \\
\text { during the } 1^{\text {st }} \text { cool-down }\end{array}$ & 4 & 34 & 30 & 68 \\
\hline $\begin{array}{l}\mathrm{Nr} \text { quenches to reach } 11080 \mathrm{~A} \\
\text { during the } 2^{\text {nd }} \text { cool-down }\end{array}$ & 1 & 3 & 4 & 8 \\
\hline
\end{tabular}

Magnets showing a low first training quench current gained on average a lot after the thermal cycle, as shown in Fig. 3; see also [13]. Magnets with a first training quench below $11.3 \mathrm{kA}$ during the $1^{\text {st }}$ cool-down always had a $1^{\text {st }}$ training quench after the thermal cycle that was larger. Only 9 out of 116 magnets showed detraining, i.e. the thermal cycle resulted in a deterioration of the quench performance.

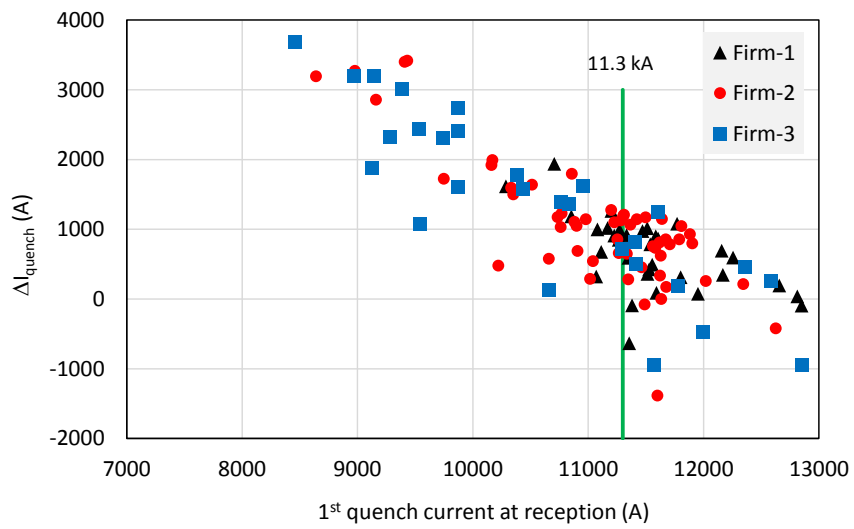

Fig. 3. Difference between $1^{\text {st }}$ training quench after thermal cycle and the $1^{\text {st }}$ training quench at reception $\left(\Delta \mathrm{I}_{\text {quench }}\right)$ plotted versus the $1^{\text {st }}$ training quench at reception.

Assuming that the magnets would have a similar behavior in the LHC, one could calculate the number of quenches to train all magnets to $11080 \mathrm{~A}$ in the LHC. This results in $(400 / 33) * 1=12$ for Firm-1, $(420 / 55)^{*} 3=23$ for Firm-2, and $(412 / 28) * 4$ for Firm-3 (denoted by Estimate A in Table VI). However, this approach is pessimistic since the data of Table $\mathrm{V}$ are biased by the fact that, on average, these magnets trained slower than the entire population. Estimate B takes this bias into account, by scaling Estimate $\mathrm{A}$ to the quench probability presented in Tables III and V. So Estimates A are scaled by a factor $(47 / 400) /(4 / 33)$ for Firm-1, a factor $(183 / 420) /(34 / 55)$ for Firm-2 and (183/412)/(30/28) for Firm3 , giving for Estimate B values of 12, 16 and 24, respectively. 
TABLE VI

Estimated Number of QuenCHES NEeded to TRAIN THE 1232 MAGNETS IN THE LHC TO $11080 \mathrm{~A}$

\begin{tabular}{lllll}
\hline \hline & Firm-1 & Firm-2 & Firm-3 & All \\
\hline Number of magnets & 400 & 420 & 412 & 1232 \\
Estimate A & 12 & 23 & 59 & 94 \\
Estimate B & 12 & 16 & 24 & 52 \\
\hline \hline
\end{tabular}

\section{TRAining OF ONE SECtOR OF THE LHC IN 2008}

In 2008 one octant of the machine (called S56), containing 154 magnets (28 magnets from Firm-1, 42 from Firm-2, and 84 from Firm-3) was trained up to 11173 A; see Table VII. A total of 24 quenches were needed to reach $11080 \mathrm{~A}$, and another 4 to reach $11173 \mathrm{~A}[14,15]$, at which current the training was interrupted. Successive quenches always occurred at a higher current except for one quench showing a detraining of 190 A. Almost all quenches occurred in Firm-3 magnets. During the initial reception tests (see Section II) the same magnets required 60 quenches. It follows that Firm-2 magnets show good memory, whereas Firm-3 magnets show partial memory. Only one of the 154 magnets in S56 was tested after a thermal cycle during the reception tests. It is, however, obvious that the Firm-3 magnets train much more than estimated by comparing the quenches in Table VII (22 quenches in 84 magnets) to the Estimate B in Table VI (24 quenches in 412 magnets). Apparently the good memory that Firm-3 magnets showed during the reception tests slowly vanished in time. In [13] it was concluded that there is no indication that the duration of the long-term storage, between reception and installation in the LHC, could have affected the performance.

TABLE VII

Quench Behavior of THE 154 Dipole Magnets in One SeCtor S56 OF THE LHC (2008)

\begin{tabular}{lllll}
\hline \hline & Firm-1 & Firm-2 & Firm-3 & All \\
\hline $\begin{array}{l}\text { Number of magnets } \\
\text { Nr quenches to reach 11080 A } \\
\quad \text { - Reception 1 }\end{array}$ cool-down & 28 & 42 & 84 & 154 \\
$\begin{array}{c}\text { Nr quenches to reach 11080 A } \\
\quad \text { LHC 2008 }\end{array}$ & 0 & 15 & 44 & 60 \\
\hline \hline
\end{tabular}

\section{TRAINING OF 8 SECTORS OF THE LHC IN 2015}

In the beginning of 2013 the LHC was warmed-up to room temperature, and in the following one and a half years all busbar interconnects were consolidated. In the end of 2014 the LHC was cooled-down again to $1.9 \mathrm{~K}$ and in the beginning of 2015 all 1232 dipole magnets in the 8 sectors of the LHC were trained up to $11080 \mathrm{~A}$. In total 175 quenches occurred; 5 in Firm-1 magnets, 27 in Firm-2 magnets and 143 in Firm-3 magnets. Successive quenches in the same circuit were always at a higher current, except for a few cases showing detraining between $0-120 \mathrm{~A}$. After the $1^{\text {st }}$ cool-down of the reception tests, the 1232 magnets required 413 quenches to reach
11080 A. Plotting the quench results per firm (in a similar way as Fig. 2), shows that Firm-1 and Firm-2 magnets have a good memory since training in the LHC is 9 respectively 7 times faster than during reception. Firm-3 magnets, however, show only partial memory with a training which is only $30 \%$ faster than during reception. During reception 75 quenches occurred in Firm-3 magnets below $10 \mathrm{kA}$; in the LHC only 7. On the other hand, the slope of the training curve between 10 and $11.1 \mathrm{kA}$ is smaller in the LHC. Note that none of the Firm-1 and Firm-2 magnets quenched twice. Among the 143 quenches in Firm-3 magnets, 120 magnets quenched once, 10 magnets quenched twice, and 1 magnet quenched 3 times. For those magnets that quenched 2 or 3 times, the $2^{\text {nd }}$ quench current was always higher than the $1^{\text {st }}$ one and the $3^{\text {rd }}$ quench current was higher than the $2^{\text {nd }}$. Comparing the number of quenches in the LHC with Estimate B (see Table VI) shows that, within about a factor 2, the training of the Firm-1 and Firm-2 magnets is in agreement to the estimate, whereas Firm3 magnets train significantly more.

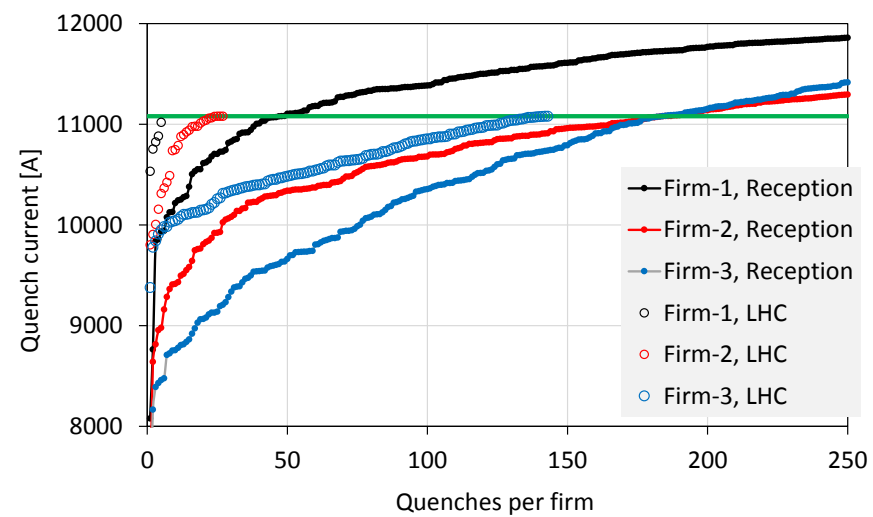

Fig. 2. Training curve to $11080 \mathrm{~A}$ for the 1232 dipole magnets in the LHC (round circles), as compared to the training during reception (solid dots). The green line corresponds to $11080 \mathrm{~A}$.

Of special interest is to compare the training of S56 in 2008 (see Section IV) with the training in 2015; see Table VIII. Note as well that 13 of the 16 quenches in Firm-3 magnets in 2015 occurred in magnets that did not quench in 2008.

TABLE VIII

COMPARISON OF THE TRAINING OF S56

\begin{tabular}{lllll}
\hline \hline & Firm-1 & Firm-2 & Firm-3 & All \\
\hline $\begin{array}{l}\text { Number of magnets } \\
\begin{array}{l}\text { Nr quenches to reach 11080 A } \\
\quad \text { LHC 2015 }\end{array}\end{array}$ & 0 & 42 & 84 & 154 \\
$\begin{array}{l}\text { Nr quenches to reach 11080 A } \\
\quad \text { - LHC 2008 }\end{array}$ & 0 & 28 & 16 & 16 \\
$\begin{array}{l}\text { Nr quenches to reach 11080 A } \\
\quad \text { Reception 1 }\end{array}$ & 1 & 15 & 44 & 60 \\
\hline \hline
\end{tabular}

Of course, the statistics are low, but one can conclude at least that despite the combined effect of time, thermal cycle, and powering (up to $6.8 \mathrm{kA}$ ) the magnets of Firm-1 and Firm2 retained their memory. Extrapolating this result implies that 
these magnets will probably need as well only a short training after future thermal cycles. The training behavior of the magnets from Firm-3 is less predictable. Many magnets with good training performance during reception show detraining in the LHC. The fact that the magnets from Firm-3 retain their quench memory only partially implies that a similar amount of training is likely needed after future thermal cycles.

Another interesting result is found by looking in detail to the Firm-3 magnets that quenched in the LHC and compare them to their behavior during reception; see Fig. 5. The horizontal axis shows the magnet ID in chronological order of production. It is clear that the behavior is not uniform over the production and that especially the magnets in the production batch 140-240 quenched more often in the LHC, and in many cases at currents several $\mathrm{kA}$ below their $1^{\text {st }}$ quench during reception. There is no clear correlation between the Firm-3 magnets that quenched during reception below $11080 \mathrm{~A}$ and those that quenched in 2015 below 11080 A. Further data analysis shows that during reception, the Set 1 of 266 magnets did not quench below $11080 \mathrm{~A}$, while the remaining Set 2 of 146 magnets quenched once or more below 11080. In 2015, 79 out of Set $1(30 \%)$ and 52 out of Set 2 (so 36\%) quenched once or more.

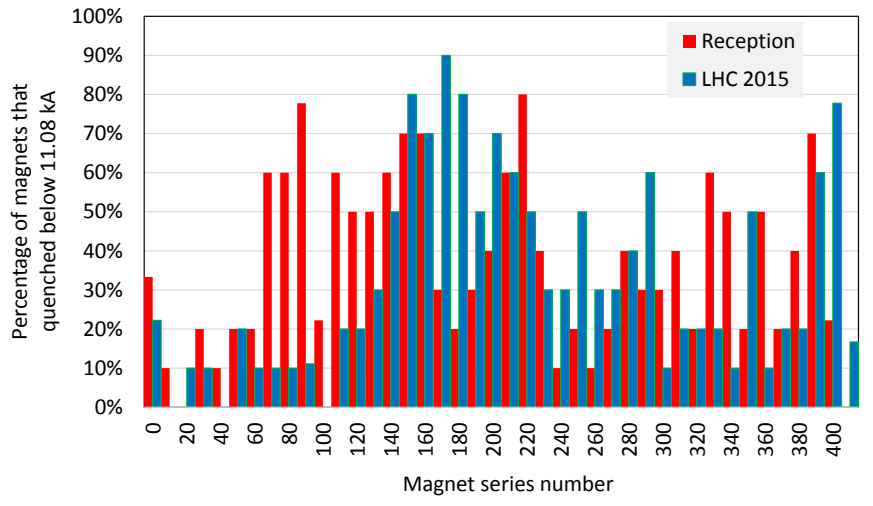

Fig. 5. Percentage of Firm-3 magnets that quenched below $11080 \mathrm{~A}$ during reception (red bars) and in the LHC (blue bars).

After the re-training of all the magnets in the LHC the 8 circuits underwent one more cycle to $11080 \mathrm{~A}$ and a few cycles to $10980 \mathrm{~A}$, as part of the hardware commissioning. During these tests, another 8 training quenches occurred at constant current, 3 of them in Firm-2 magnets and 5 in Firm-3 magnets. After the commissioning the LHC has been operated with daily current cycles to the nominal current of $10980 \mathrm{~A}$. In the first 4 months, 4 more training quenches occurred at nominal current, all of them in Firm-2 magnets, possibly related to slow relaxation processes, setting the cable or coil in a more stable position.

\section{CONCLUSION}

This paper presents a brief overview of the training behavior of the $15-\mathrm{m}$ long $\mathrm{Nb}$-Ti dipole magnets of the LHC, which have been assembled by three different firms, with only few minor differences in tooling and procedures. The quench data of the reception tests in 2002-2007, and two training campaigns in the LHC (in 2008 and 2015) are summarized for training up to $11080 \mathrm{~A}$. This resulted in a unique data set containing more than 1200 magnets stretching over a period of more than ten years including several thermal cycles and hundreds of powering cycles. The data show that the magnets of Firm- 1 and Firm-2 train 7-9 times faster in the LHC in 2015 as compared to the reception tests. These magnets almost completely retain their quench memory over the past 10 years. This would of course be very beneficial for future training campaigns. The magnets from Firm-3 train only about 1.3 times faster in the LHC as compared to the reception, but also in a very unpredictable way. Many magnets with good training performance during reception show detraining in the LHC, in many cases up to several kA. It seems very likely that a significant number of the Firm-3 magnets will train again after future long shutdowns of the LHC. In the meantime, investigations are ongoing to better understand the origin and possibly propose ideas for faster training.

In the first 5 months of LHC operation, 4 training quenches occurred at a constant current of $10980 \mathrm{~A}$, which is from an operational point of view acceptable.

\section{ACKNOWLEDGMENT}

The authors want to thank all people that have been involved in the reception tests of the dipole magnets and all people involved in the Hardware Commissioning of the LHC.

\section{REFERENCES}

[1] LHC design report, CERN-2004-003 (2004).

[2] A. Ballarino, "HTS current leads for the LHC Magnet Powering System", Physica C, Vol. 372-376, pp. 1413-1418 (2002).

[3] D. Leroy, "Review of the R\&D and supply of the LHC superconducting cables", IEEE Trans. Appl. SC, Vol. 16, No. 2, pp. 1152-1159 (2006).

[4] F. Savary et al., "Description of the main features of the series production of the LHC main dipole magnets", IEEE Trans. Appl. SC, Vol. 18, No. 2, pp. 220-225 (2008)

[5] R. Denz, "Electronic Systems for the Protection of Superconducting Elements in the LHC", IEEE Trans. on Appl. SC, Vol. 16, no 2, pp. 1725-1728 (2006).

[6] K. Dahlerup-Petersen et al., "Energy Extraction for the LHC superconducting circuits", Proc. PAC 2001, Vol. 5, pp. 3448-3450 (2002).

[7] V. Chohan, "Testing of the LHC magnets in cryogenic conditions: operation challenges, status and outlook", Proc. PAC 2005, pp. 250-252 (2005).

[8] R. Saban et al., "The Commissioning of the LHC Technical Systems", Proc. PAC 2007, pp. 3801-3803 (2007).

[9] A. Verweij, et al., "Performance of the main dipole magnet circuits of the LHC during commissioning, Proceedings EPAC08 (2009), LHC Project Report 1140 (2008)

[10] $\mathrm{Ph}$. Lebrun et al., "Report of the task force on the incident of 19 September 2008 at the LHC", LHC Project Report 1168 (2009).

[11] F. Lackner et al., "Consolidation of the 13-kA Superconducting Magnet Circuits of the LHC at CERN", IEEE Trans. Appl. SC, Vol. 25, No. 3 (2015).

[12] P. Pugnat, A. Siemko, "Review of Quench Performance of LHC Main Superconducting Magnets", IEEE Trans. Appl. SC, Vol. 17, No. 2, pp. 1091-1096 (2007).

[13] C. Lorin, A. Siemko, E. Todesco, A. Verweij, "Predicting the Quench Behavior of the LHC Dipoles During Commissioning", IEEE Trans. Appl. SC, Vol. 20, No. 3, pp. 135-139 (2010).

[14] A.P. Verweij, "Training the dipoles", Proceedings LHC Performance Workshop - Chamonix 2009.

[15] B. Bellesia, N. Catalan Lasheras, E. Todesco, "Magnet (re)training", Proceedings LHC Performance Workshop - Chamonix 2009. 